\title{
Watercraft Commanding Simulation Laboratory Team training Mode Research and Application
}

\author{
Wang Shanbin \\ (Zhenjiang Watercraft College, Zhenjiang Jiangsu 212003) \\ (Email: wangsbb@tom.com; Tel: 0511-85330706)
}

Keywords: simulation laboratory, team training mode, application mode

Abstract: The author analyzes the domestic and foreign situation and development trend in the simulation training area, It expounds the shipment command situation laboratory team training mode of the background and content researchins, Proposes the important views for the shipment command simulation laboratory team training mode's theory, applications and practice methods etc. Such as that list 16 distributions of shipment command team training course names,contents and ways.

Army colleges and universities transform from academic education to the professional education, the core was to shift from focusing on the basic theory academic education to "close to army training education", the process of talent training is extend to troops, the troops need "classrooms" to research the real military struggle preparation and to train to win the modern war. Closely combining the reality of Navy training, in order to improve the students' command capability, operation skills and ability to settle complicated situation, thus to improve the boat troops support capability, to achieve

"military training to produce highly skilled military personnel" goal. Around this ambition, we started to research the command ship driving simulation laboratory organization mode, to form the new theoretical knowledge, to explore the feasibility of implementation, and to improve the boat talent training quality effectively.

The domestic and foreign present situation and development trend analysis

The rule of military training transforming in the world, we can see that all the military forces are pay attention to imitative training. They spend lots of manpower, resources and technologies to research and explore new theory, new methods of simulation training all the time. In general, the development of simulation training has the trends as follow: Firstly,simulation for all the area, to promote changes of military training.Simulation training has reached the target of the weapon operation training, professional and technical training, battle command training, tactical training and etc. It will deeply change the training concepts, theories, methods and contents. Secondly, it is to be combat simulation, the fighting starts from the laboratory. By using the modern simulation 
technology, described and simulated the future combat environments, actions,processing as well as weapons and equipment characteristics, make the trainees to get approximate actual combat live-fire exercise training place.Thirdly, the integration of simulation can achieved to fight capacity of the system integration. Simulation of a single system or simulator, generally have only a single training function cannot meet unite fight and system fighting requirements. In order to solve this problem, foreign army generally take the network technology, the various single simulation system to connect or emulator, integrated simulation training, so that will achieve to increase the total

fighting capacity from system integration. Finally, the virtual reality simulation make the training to the combat. Integrated use of virtual reality technology such as accoustic, vision and tactile make trainees to generate a very realistic virtual environment in the future war, the trainees provided a variety of difficulties, and despair at high-risk situation, a comprehensive simulation exercises various action of high risk, it will improve the ability to deal with emergencies of all kinds of risk, make the trainees to maximize the approximate actual combat training.

According to the development trend and applications of simulation training in the world, review the institute of boat university in simulation training through ten years, in the transformation of education, launch "colleges and universities education close to the Navy forces", Simulation laboratory in the college's teaching concept, pattern and content will get a strong impact. how to exert the maximum efficiency for simulation lab under a new situation is the starting point of our research.

\section{The ship driving simulation laboratory organization team simulation research background}

After many years of teaching practice, the university provide a very good teaching practice platform due to the ship driving simulation lab. It is greatly improving the quality and efficiency of training. However, ship driving simulation laboratory in training and organization mode can't fully meet the military training reform requirement since reform of military training and college education transformation. According to the transformation of school education and the reform of military training establish a "build for the war, teach for the war, research for the war, practice for the war" , Recently,we are on the basis of the existing simulation laboratory, reform of ship security command and synergy in action and disposal of the training mode of complex conditions, and application of it in teaching practice have achieved good teaching effect.

The ship driving simulation laboratory organization team simulation research contents

3.1 The ship driving simulation laboratory organization team simulation research theory

In technology and the command ship driving simulation training system under the guidance theory, 
based on the simulation training system technology and the ship driving command information resources, in order to guide the member (teachers or coaches) as the leading factor, to trainees (students) as the main body, in order to improve the ability to guide the member guide training and training ability of the trainee, the training include problem-solving skills, creative ability, flexible ability and so on."college education at the same time close to the forces" for the education transforming purpose, to "fighting and winning " as the goal, on the basis of the previous research results, the foundation for simulation training practice and research to explore the command ship driving simulation laboratory organization mode of theory and practice, and service for "high-quality ship military talents training", promote educational level and quality of personnel training.

Structure in the figure as follows:

Teaching Ship command knowledge and skills

\section{Open System}

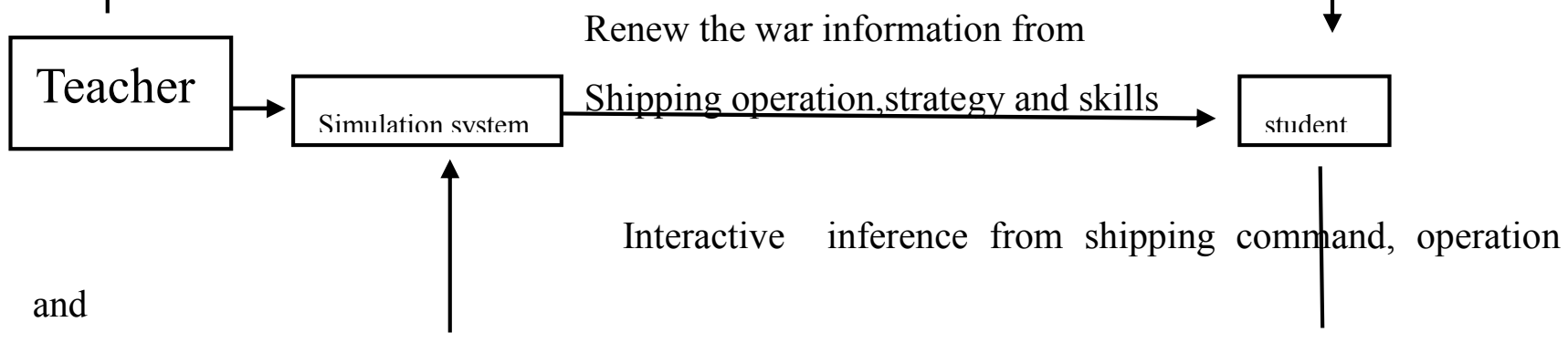

skills

3.2 The ship driving simulation laboratory organization team simulation research acting point

Command ship driving simulation laboratory training mode in training outstanding advantage, make the universities, forces to carry out the simulation training mode for more urgent. So, how to improve the quality and efficiency of education training? We think there are three acting pints as follows:

Determine the team training application strategy in the simulation lab

Ship driving command is involved to the operation, coordination subjects. which content is suitable for simulation training? which needs to retain traditional live-fire training mode? It required the overall research and design, forming a set of effective strategies, to ensure the simulation laboratory training mode to get steady progress.

The organization model simulation laboratory around training course

Around training course characteristics, study how to carry out simulation laboratory organization 
mode, arouse the enthusiasm of trainees interesting, cultivate trainees to find problems, be able to analyze and solve problems of boat command, control, and collaborative.

\section{impeccable technical platform and unite training}

Due to single function of the simulation system can't meet the future information war unite operations against system requirements. In terms of system interface compatibility, we study how to effective power, boat equipment and boats and vessels weapons uni-com, to achieve the goal of integrated simulation training. On this basis, to create interactive organization mode, forming simulation system, guide the interaction between the trainers and trainees.

The ship driving simulation laboratory organization team simulation application mode

Ship driving command of curriculum is complicated, different categories of course, different teaching goal, content, structure, and study requirements, the applicable organization mode is different too. we go through a single ship training simulation training subjects which were part of the organization, as a special case, and lists the training content and methods.

\section{1 sailing preparation}

Training content: prepare sailing of procedures, methods, and the main points for sail preparation.

Training way: to organize the implementation, in the form of single ship training guide the member (faculty) will be simulated department director (director) into ship forces command, instructions of different duty task voyage, the simulated boat according to the procedures related to prepare for sea, report step by step. Training can take "practice- comment- practice-comment--test" program.

4.2 the ship tactical technical performance test

Training content: ship inertial impact distance measurement; The determination of ship cycle elements; Speed measurement.

Training way: in the form of a single ship training organizations, in accordance with the organization method. the tactical technical performance measurement methods organize the implementation of simulated training system. According to the needs of training methods set up corresponding wind conditions, organization simulation ships, back and forth using radar, electronic chart corresponding movement distance measurement. Select different type of craft training object and organization training, but the issue is how to select the system program, simulation of the boat tactical technical performance is not match the real boat function. therefore, the subject is focus on know methods and processes.

\subsection{Ship operation}

Training content: Ship reach and leave the port manipulation, anchor handling manipulation 
Training way: in the form of a single ship training organizations, in accordance with the organization command methods of various types of manipulation, using the simulation training system set up the corresponding training scenario, can be in the order from easy to difficult, difficult and complex conditions gradually improved training, to exercise and improve the ability of boat command and control and the coordinated ability.Command ship manipulation training course is relatively mature, a more realistic scenario, effective organization can save testing result of training time and strength. This subject training, not only to konw the methods, but also learn the knowledge of the cable, blunt, wind and other factors on the impact of boats manipulation.

\section{4 sailing in normal}

Training content: this unit is waters, harbor, anchorage navigation sailing training. Training way: in the form of a single ship training organizations, set up corresponding training scenario simulation training system. It can add some parameters related to the inspection standard training, such as the observation of the target of sea, air, and reports, you can set some aircraft, ships and floating target;Basic rules, such as familiar with navigation can be in and out of the harbour, the anchorage requirements, such as setting parameters and the corresponding training evaluation indexes.
Navigation
under
complicated
conditions

Training content: sailing in a reef area, narrow waterway, night and fog,stormy waves. Training way: in the form of a single ship training organizations, using electronic chart system to choose the jurisdiction reef area, narrow channel and other complex security waters, or the typical complex waters (e.g., the zhoushan islands), using the simulation training system set up at night and fog restricted visibility when visual training;Set the waves level;Set a target parameters such as ship, obstruction;According to the training program of assessment contents and standards, organize the implementation of the training.

life

saving

Training content: staff rescue for victim.

Training way: in the form of single ship training organizations, using the simulation training system setup man overboard or surface targets;Set the wind and waves level and corresponding target parameters;According to the case scenario of life-saving, organization, command, ship maneuvering, deck crew coordination steps to organize and implement training (can take side assistance, cast gate assistance organization) in two ways.

personnel

search

and

rescue

Training content: staff rescue with organizing and action. 
Training way: in the form of single ship training organizations, choose suitable for simulation training of water and weather conditions according to the display;According to the rescue report receiving (or rescue command from a superior), organization, preparation, ships sailing, rescuing, close to the victim, the implementation of the rescue drowning process training; be induced by scenarios, set the appropriate water targets, meteorological and hydrological conditions, such as obstacles, organize personnel to the different stages of the search and rescue training, induction will be conformed to the actual situation.

\section{Conclusion}

According to the command ship driving simulation laboratory study and the specific application, to reduce the differences of "classroom" and "the battlefield" environment, and from the "simulation technology and the integration of professional training," it promotes the command ship driving professional training course and transforms training mode from the traditional training mode to modern training mode, to build the simulation training mode with command ship driving professional characteristics, made significant training effect, to carry out simulation training provides a new thinking, new ways, new paradigm, to improve the quality of college education and talents cultivation.

\section{References:}

[1] Wang Shanbin zhang kai, etc. Keep in mind the army boats mission, and strive to build emergency operations integration simulation training environment. Army boat. 2005 [2] Wang Shanbin. Boat command informationization teaching pattern of professional research. Zhenjiang boat college journal. 2011, no. 2 